EDITORIAL

\title{
CALIDAD Y EDUCACIÓN SUPERIOR: DESAFÍOS EN LA FORMACIÓN DE INGENIEROS EN EL SIGLO XXI
}

La educación superior en Chile ha experimentado un notable éxito en el incremento de la cobertura y un mejoramiento significativo en el acceso de los grupos más vulnerables. En efecto, mientras en el año 1990 sólo cerca de un 15\% de los jóvenes entre 18 y 24 años accedían a la educación superior, hoy esta cifra bordea el 37\%. Similarmente, mientras en esa misma fecha menos del 5\% de los jóvenes de más escasos recursos llegaban a la educación superior, en la actualidad esa participación se acerca al 15\%. En la actualidad se gradúan más de 24.000 personas al año, cifra que no alcanzaba a los 9.000 estudiantes egresados en el año 1995.

La creciente consolidación del sistema de instituciones privadas, así como la implementación de políticas públicas han permitido un mejoramiento cuantitativo significativo. Por otro lado, los esfuerzos en el mejoramiento de la calidad no han estado ausentes en el sistema; por el contrario, el trabajo del Consejo Superior de Educación (CSE), el proceso piloto de la Comisión Nacional de Acreditación de Pregrado (CNAP) y postgrado (CONAP) han sido aportes valiosos y decididos en procura de colocar el acento en el equilibrio necesario entre cobertura y calidad de la educación superior. Por su parte, los programas Ministeriales tales como Fondos de Desarrollo Institucional y, más recientemente, el programa de Mejoramiento de la Calidad y Equidad de la Educación Superior (MECESUP) han permitido un salto cualitativo que es susceptible de ser apreciado desde Arica a Punta Arenas.

Los antecedentes objetivos muestran una educación superior que permite un acceso más amplio a los distintos sectores económicos, y una serie de acciones tendientes a fortalecer la calidad y la equidad. Sin embargo, los desafíos estratégicos en esta materia siguen siendo de la mayor envergadura.

Ciertamente, no se puede desconocer que en la educación superior existe asimetría de información, la formación de profesionales o la creación de conocimiento no es un servicio indiferenciado ni estrictamente divisible, no hay perfecta movilidad de los recursos, los costos de cambio son significativos, existen costos de transacción, y los usuarios que toman una decisión incorrecta pueden perder oportunidades únicas de desarrollo personal y profesional. Más importante aún, tras la elección de carreras por parte de los estudiantes, hay sueños, hay ilusiones, hay vidas de personas y familias que se entregan por completo en la búsqueda de la movilidad social.

En consecuencia, el Estado debe garantizar la fe pública. Debe existir un sistema de información que proporcione los antecedentes suficientes y necesarios para quienes optan por seguir determinadas profesiones en determinadas instituciones. Se debe garantizar que las instituciones y los programas de pregrado y postgrado del sistema cumplen de manera satisfactoria con estándares de calidad que le permiten crear conocimiento, difundir este conocimiento y formar profesionales y capital humano avanzado, con niveles adecuados de idoneidad. Complementariamente, es posible sostener que los imperativos que emergen de la inserción de nuestro país en los grandes mercados internacionales suponen exigencias crecientes en la formación de capital humano avanzado y en la creación y aplicación de conocimiento. Por cierto, en la sociedad del conocimiento, el capital humano y sus capacidades para crear, transmitir y aplicar conocimientos, constituyen la fuente esencial de la ventaja competitiva para las naciones, para las organizaciones y para las personas.

En consecuencia, el surgimiento y la consolidación de un sistema nacional de aseguramiento de la calidad es un imperativo estratégico para el país. Este imperativo se ha abordado con éxito generándose la ley $\mathrm{N}^{\circ} 20.129$, la que ha logrado un alto grado de consenso en amplios sectores de la sociedad. Hoy comienza por lo tanto, con más fuerza que nunca, un énfasis ineludible en la calidad de la educación superior. 
En este contexto, los desafíos para la Comisión Nacional de Acreditación (CNA-Chile) son mayores, y requieren de un trabajo en equipo, en un marco de pluralismo y respeto por la diversidad, con vigor intelectual, con altura de miras y teniendo por norte el interés del país. Finalmente, la Comisión Nacional de Acreditación (CNA-Chile) debe articular su trabajo con el Consejo Superior de Educación y con la propia División de Educación Superior del Ministerio de Educación para consolidar un sistema nacional de aseguramiento de la calidad que responda a los requerimientos nacionales y que contribuya a facilitar la inserción competitiva de Chile en los mercados mundiales.

El área de ingeniería no está exenta de estos desafíos. En efecto, la inserción de Chile en los grandes mercados internacionales tiene exigencias mayores en la formación de profesionales en el campo de las ciencias de la ingeniería e ingeniería aplicada. Para que Chile logre generar valor agregado a sus exportaciones se requiere avanzar en la industria manufacturera, de servicios, y en los mercados del conocimiento. Los ingenieros del país están llamados a adoptar un rol protagónico en esta dimensión. Se requieren, por tanto, profesionales con sólidos conocimientos en ciencias básicas, y en sus respectivas especialidades, pero sin perder de vista las exigencias que la sociedad actual impone tales como habilidades sociales, capacidades de emprendimiento, dominio del idioma inglés, ética, capacidad para innovar y para trabajar en equipo, capacidad para liderar equipos.

En la sociedad del conocimiento, los ingenieros no son sólo grandes dominadores de contenidos de especialidad y expertos en ciencias básicas, son mas bien personas con talentos y capacidades amplias que pueden desplegar a favor de una organización, contribuyendo decisivamente al desarrollo del país.

La calidad en la formación de ingenieros en el siglo XXI se refiere a la consolidación de profesionales con conocimientos, habilidades y destrezas que se ponen al servicio de las organizaciones, del emprendimiento, y del país.

Manuel J. Donoso Muñoz

Vicerrector de Administración y Finanzas

Universidad de Tarapacá

Arica, Chile
Emilio R. Rodríguez Ponce Presidente

Comisión Nacional de Acreditación

Arica, Chile 